Article

\title{
Air Travel and Urbanity: The Role of Migration, Social Networks, Airport Accessibility, and 'Rebound'
}

\author{
Giulio Mattioli ${ }^{1,3, *}$, Craig Morton ${ }^{2}$ and Joachim Scheiner ${ }^{1}$ \\ ${ }^{1}$ Department of Transport Planning, TU Dortmund University, 44227 Dortmund, Germany; \\ E-Mails: giulio.mattioli@tu-dortmund.de (G.M.), joachim.scheiner@tu-dortmund.de (J.S.) \\ 2 School of Architecture, Building and Civil Engineering, Loughborough University, Loughborough, LE11 3TU, UK; \\ E-Mail: c.morton@lboro.ac.uk \\ ${ }^{3}$ School of Earth and Environment, University of Leeds, Leeds, LS2 9JT, UK \\ * Corresponding author
}

Submitted: 30 December 2020 | Accepted: 8 March 2021 | Published: 9 June 2021

\begin{abstract}
Residents of urban areas, and particularly urban cores, have higher levels of long-distance travel activity and related emissions, mostly on account of greater frequency of air travel. This relationship typically remains after controlling for basic socio-economic correlates of long-distance travel. There is an ongoing debate in the literature about what causes this association, and whether it calls into question urban densification strategies. Understanding this is important from a climate policy perspective. In this article, we investigate the role of three factors: i) access to airports; ii) the concentration of people with migration background and/or geographically dispersed social networks in urban areas; and iii) greater air travel by urban residents without cars ('rebound effect'). We use representative survey data for the UK including information on respondents' air travel frequency for private purposes and derive estimates of greenhouse gas emissions. The dataset also includes detailed information on migration generation, residential location of close family and friends, car ownership and use, as well as low-level geographical identifiers. The findings of regression analysis show that Greater London residents stand out in terms of emissions from air travel. Airport accessibility, migration background, and dispersion of social networks each explain part of this association, whereas we find no evidence of a rebound effect. However, proximity to town centres remains associated with higher emissions after accounting for these issues, indicating that this association is due to other factors than those considered here. We conclude by discussing implications for urban and climate policy, as well as future research.
\end{abstract}

\section{Keywords}

airport accessibility; air travel; greenhouse gas emissions; long-distance travel; migrants; rebound effect; social networks; travel behaviour; visiting friends and relatives

Issue

This article is part of the issue "Cities, Long-Distance Travel, and Climate Impacts" edited by Jukka Heinonen (University of Iceland, Iceland) and Michał Czepkiewicz (University of Iceland, Iceland / Adam Mickiewicz University in Poznań, Poland).

(C) 2021 by the authors; licensee Cogitatio (Lisbon, Portugal). This article is licensed under a Creative Commons Attribution 4.0 International License (CC BY).

\section{Introduction}

Climate change mitigation in the transport sector is particularly challenging, due to ever-increasing levels of travel activity, which tend to offset improvements in the energy efficiency and carbon intensity of vehicles. This trend is particularly pronounced for aviation, where emissions have increased rapidly, and technological solutions are in short supply.

There is a long tradition of urban and transport planning research arguing that large, compact cities are better placed to reduce carbon emissions and other negative environmental impacts from transport. Most of this literature, however, refers to everyday travel 
and specifically to lower levels of car use in dense urban areas. Yet, an emerging body of research shows that levels of long-distance travel are higher in large cities and urban cores, which can offset lower emissions from everyday travel. Czepkiewicz, Heinonen, and Ottelin (2018) review this literature, and find that this is mostly due to urban residents travelling more internationally by air, and that the association cannot be entirely accounted for by basic differences in socio-economic composition (e.g., higher income and education).

As a result, there is an ongoing debate about what other factors are responsible for greater levels of longdistance travel, and notably air travel, among urban residents. Several hypotheses have been put forward to explain this association, although only scant evidence exists to support them (as discussed in Section 2). Some posit the existence of a direct link between built environment characteristics and greater levels of long-distance travel. This, if confirmed, would question the assumption that urbanisation and compact city policies contribute to climate change mitigation in the transport sector. Other hypotheses posit that the association between urbanity and long-distance travel is spurious, i.e., accounted for by other factors. Understanding which explanation is empirically supported is thus key from an urban planning perspective. Getting a better grasp of the determinants of air travel among urban residents also helps shed light on what is driving the rapid increase of air travel emissions globally.

This article presents a study on greenhouse gas (GHG) emissions from personal air travel, which investigates the role of three factors: i) access to airports; ii) the concentration of people with migration background and/or geographically dispersed social networks in urban areas; and iii) greater air travel by urban residents without cars (often referred to as 'rebound effect').

As such, the article makes four contributions to existing knowledge. First, it simultaneously explores three plausible mechanisms responsible for the association between urbanity and air travel, which have rarely been examined before.

Second, we use data from a large survey that is nationally representative, unlike many previous studies in this area that relied on smaller, ad-hoc surveys. This has advantages in terms of the robustness and generalizability of the results.

Third, our study focuses on England (the largest constituent country of the UK), which is interesting in several respects. Due to population size and high levels of air travel per capita, the UK is responsible for $4 \%$ of global $\mathrm{CO}_{2}$ emissions from commercial aviation, second only to the US and China (Graver, Zhang, \& Rutherford, 2019). England includes a diversity of urban areas, ranging from small towns to large conurbations to the global city of London. This helps us investigate how levels of air travel vary across the urban-rural continuum.

Finally, the availability of small-area geographicidentifiers enables us to simultaneously investigate dif- ferences across the urban-rural continuum as well as within urban areas (i.e., depending on proximity to town centres), two aspects that have often been explored separately.

In the next section, we provide a short review of the literature on the relationships between urbanity, air travel, and the factors under investigation.

\section{Background}

A growing body of literature has explored the association between urbanity and long-distance leisure travel. Czepkiewicz, Heinonen, et al. (2018) provide an excellent recent review of 27 studies on this topic, to which the reader is referred for more information. In the remainder of this section, we focus more specifically on the theoretical explanations researchers have put forward for this association. Czepkiewicz, Heinonen, et al. (2018) identify five different explanations:

1. A 'rebound effect' for reduced car ownership and driving, whereby less expenditure on motoring among urban residents results in more longdistance travel by other modes, notably by air;

2. The 'compensation hypothesis' whereby people compensate for deficiencies in urban environments by 'escaping' the city more often;

3. Better access to long-distance transport infrastructure, including airports;

4. Lifestyles and socio-psychological characteristics (e.g., cosmopolitan attitudes) that are more prevalent among urban residents, while also inducing more long-distance travel;

5. Greater dispersion of social networks among urban residents.

Two observations are in order. First, assessing the relative importance of the different explanations has implications for urban planning. If rebound and compensation effects played a major role, this would question the assumption that urbanisation and compact city policies are beneficial for climate change mitigation in the transport sector. If other factors were prevalent, this would not necessarily be the case. Second, Czepkiewicz, Heinonen, et al. (2018, p. 21) conclude that there is "currently not enough evidence to decisively support any of these explanations." In this article, we add to this literature by investigating the impact of accessibility to airports, social network dispersion, and rebound effect of non-car ownership on air travel. In the remainder of this section, we briefly review existing evidence on each of these factors.

Regarding airport accessibility, to the best of our knowledge, only one previous study examined this factor in the context of debates on long-distance travel and urbanity (Bruderer Enzler, 2017). It finds that, among Swiss residents, GHG emissions from air travel for private purposes are positively associated with proximity to and 
passenger volume of the closest airport, even after controlling for population density. The author of the study speculates that this might be due to a residential selfselection effect, whereby those who live near airports have personal social networks that are more spatially dispersed. The study, however, does not control for this possible confounding factor, so that no firm conclusion can be drawn on this point.

Empirical evidence is ambiguous on the existence of a rebound effect of non-car ownership on air travel. Based on a bivariate analysis of travel survey data, Ottelin, Heinonen, and Junnila (2014) find that emissions from flying can offset the gain from reduced driving for middle-income residents of the densest parts of Helsinki (Finland). They argue that this may be due to "a trade-off between private driving and air travel...based on a simple rebound-effect of consumption" (Ottelin et al., 2014, p. 7). In a subsequent econometric modelling study, Ottelin, Heinonen, and Junnila (2017) find further evidence for this hypothesis, based on Finnish budget survey data. Other multivariate studies based on travel behaviour data, however, have typically found a neutral (e.g., Bruderer Enzler, 2017; Czepkiewicz, Klaas, \& Heinonen, 2020; Czepkiewicz, Ottelin, et al., 2018) or positive association (e.g., Czepkiewicz, Árnadóttir, \& Heinonen, 2019; Czepkiewicz, Heinonen, Næss, \& Stefansdóttir, 2020; Reichert \& Holz-Rau, 2015) between car ownership and air travel, which challenges the rebound hypothesis.

While often mentioned in the literature, there is little empirical evidence to support or reject the hypothesis that urban residents fly more in order to maintain spatially dispersed social networks. Recent quantitative empirical studies in Helsinki and Reykjavík (Iceland) find that cosmopolitan attitudes (i.e., the importance attributed to experiencing different places and cultures) account for much of the association between urbanity and international leisure travel (Czepkiewicz et al., 2019; Czepkiewicz, Klaas, et al., 2020). For some at least, cosmopolitan attitudes might be caused by international interconnectedness and dispersion of social networks, although the reverse causal link is possible as well. Czepkiewicz, Heinonen, et al. (2020) find qualitative evidence that dispersion of social networks is a driver of international travel among urban dwellers.

A related factor is migration background. Migrants typically have personal relationships that span across borders and tend to travel more by air (e.g., Bruderer Enzler, 2017; Demoli \& Subtil, 2019; Hunecke \& Toprak, 2014). Greater levels of air travel in cities may thus reflect the overrepresentation of migrants in large urban areas. Migration background can thus be seen either as a socio-demographic confounder that is generally omitted from the analysis, or as a proxy for the dispersion of social networks. To the best of our knowledge, this study is the first to explicitly investigate the role of migration background as an intervening factor in the relationship between long-distance travel and urbanity.

\section{Research Hypotheses}

Our study is oriented by two sets of hypotheses, derived from the literature. First, we expect to find an association between higher levels of GHG emissions from air travel and residence in: a) large urban areas; and b) in closer proximity to town centres, even after controlling for basic socio-economic correlates of air travel. This hypothesis is grounded in previous research-recently reviewed by Czepkiewicz, Heinonen, et al. (2018) - which has found a net association between residence in large urban areas and long-distance travel. Some of these studies (e.g., Bruderer Enzler, 2017; Demoli \& Subtil, 2019; Reichert \& Holz-Rau, 2015) find a net association between residence in large urban areas and air travel more specifically. Further studies have investigated differences within urban areas, finding a net association between living in proximity to the city centre and international travel (Czepkiewicz et al., 2019; Czepkiewicz, Heinonen, et al., 2020; Czepkiewicz, Klaas, et al., 2020; Czepkiewicz, Ottelin, et al., 2018). In this context, the contribution of our study is to test these hypotheses for a country (England) for which limited evidence exists to date.

We advance the state-of-the-art by testing a second set of hypotheses, concerning the factors responsible for the association between urbanity and air travel emissions. More specifically, we expect the association to be accounted for by: a) an overrepresentation of people with migration background and/or geographically dispersed social networks; b) better accessibility to airports; and c) lower levels of car ownership and use (resulting in a 'rebound effect'). As discussed in Section 2, while these hypotheses have been put forward in the literature, only scant evidence exists on the confounding role played by accessibility to airports, migration background, and social network dispersion, while evidence on the rebound effect is conflicting.

\section{Data and Methods}

\subsection{Data}

We analyse data from the UK Household Longitudinal Study (UKHLS; University of Essex \& Institute for Social and Economic Research, 2018a), a nationally representative, general-purpose survey providing information on a range of topics, which are not usually found together in the same dataset. While our analysis is crosssectional, we combine variables on personal social networks from Wave 3 (2011-2012) with other variables from Wave 4 (2012-2013). Our sample is therefore restricted to respondents included in both waves and weighted accordingly. UKHLS provides geographic identifiers of respondent residence at the level of Lower Layer Super Output Areas (LSOA), i.e., small, homogeneous census units, including on average 1,500 inhabitants (University of Essex \& Institute for Social and Economic 
Research, 2018b). We use LSOA identifiers to link respondents to geographical information, as described below, except for the urban-rural classification, which is based on Output Area (OA) level data and provided as part of the UKHLS dataset (University of Essex \& Institute for Social and Economic Research, 2019). As several of the spatial variables used in our analysis are not available in comparable form for Scotland, Wales, and Northern Ireland, we exclude these regions from our analysis, and focus on England only (Figure 1). After listwise deletion of missing data, our sample consists of 16,696 English residents aged 16 or older.

The dependent variable in our analysis is GHG from private air travel. UKHLS respondents to Wave 4 (2012-2013) reported the number of flights they had taken in the previous 12 months 'for leisure, holidays or visiting friends or family, distinguishing between flights within the UK, to European countries and to countries outside of Europe (travel 'for work or business purposes' was explicitly excluded). We adopt the approach developed by a study that used the same data (Alcock et al., 2017) to assign representative flight distance values to the three types of destinations. We then estimate GHG for each respondent, based on UK Government GHG conversion factors for domestic, short haul international, and long-haul international flights (Department for Environment, Food and Rural Affairs \& Department of Energy and Climate Change, 2015). We add up the estimated emissions for flights within the UK, to European countries and to countries outside of Europe into a single variable, to derive the respondent's GHG emissions from air travel in the 12 months prior to the

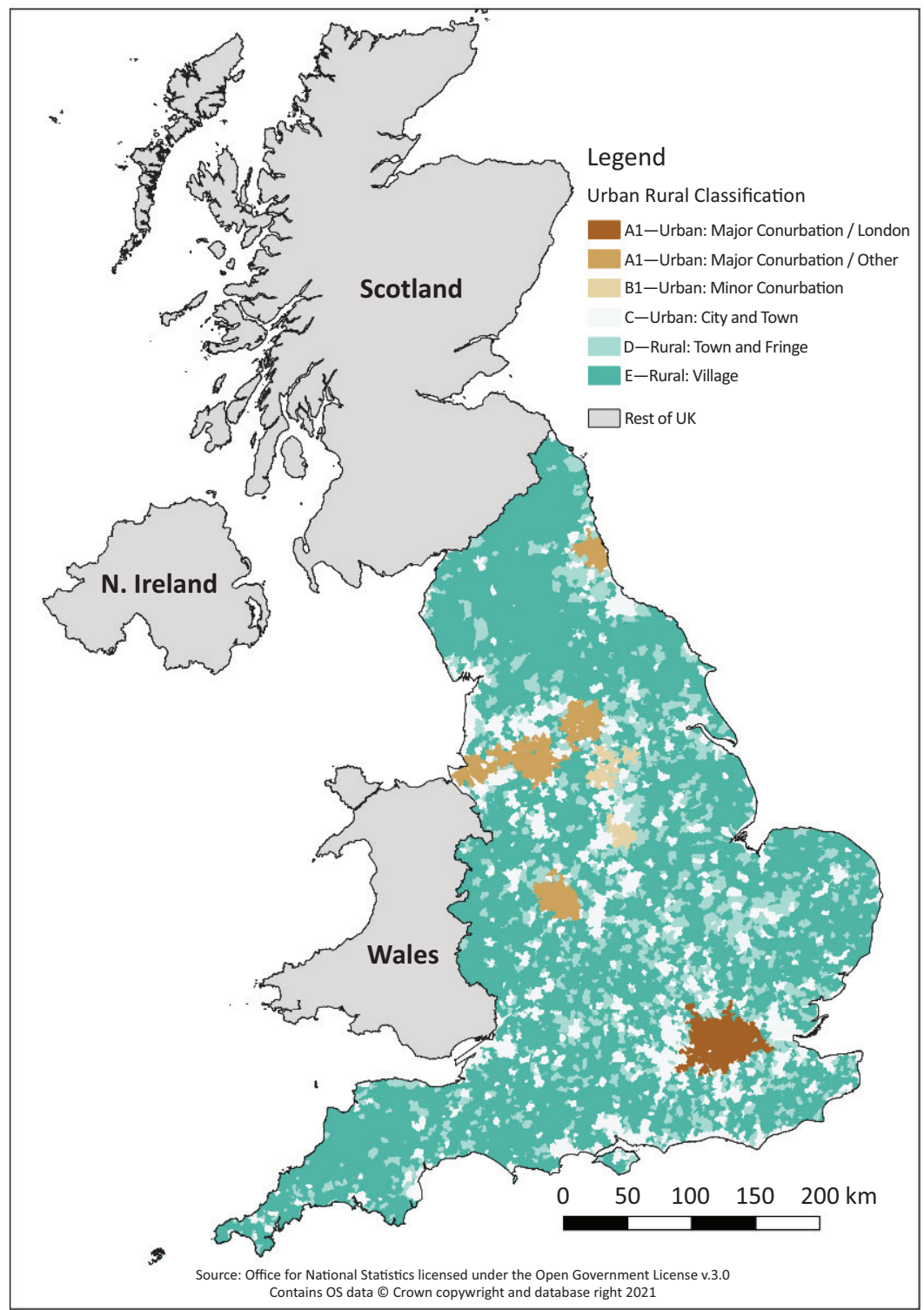

Figure 1. England and other constituent nations of the UK, with English urban-rural classification. Source: Own elaboration based on Office for National Statistics (2013). Note: 'Category F-Rural: Hamlets and Isolated Dwellings' is not shown in the map due to a discrepancy between the OA-level urban-rural classification included in the UKHLS household dataset and the publicly available LSOA-level urban-rural classification. 
interview (in $\mathrm{kgCO}_{2} \mathrm{e}$ ). For details on travel distance and GHG estimation and imputation see Table SM1 in the Supplementary File. Due to the nature of the data, the resulting variable is only an approximation of GHG emissions from air travel. It is however useful in that it allows us to 'weight' information on air travel frequency in a way that reflects the associated climate impact. As sensitivity analysis, we have repeated the analysis using a count variable (number of flights, all destinations confounded), obtaining results that are broadly consistent with those presented here.

Our analysis includes five sets of predictors. First, spatial variables covering the degree of urbanity of the respondents' residential area. For this we include two variables. First, the 2011 rural-urban classification which distinguishes between different types of rural, urban and conurbation areas (Figure 1). We further differentiate between Greater London and other conurbations, on account of London's top position in the urban hierarchy. We complement the rural-urban classification with a continuous variable measuring proximity to the nearest town centre. This allows us to further distinguish, within each type of area, between respondents that are in more or less close accessibility to town centres. We draw this information from the UK Government 'Journey Time Statistics' on travel time from each LSOA to the nearest town centre by public transport or walking (whichever is the quickest) for 2014 (Department for Transport, 2019). The Journey Time Statistics adopt a definition of 'town centre' that is based on four criteria: economy (type of employment), property (building density), diversity of use, and visitor attractions (for details see ODPM \& Centre for Advanced Spatial Analysis, 2002; Thurstain-Goodwin \& Unwin, 2000). Large urban and metropolitan areas in England (including Greater London) have more than one 'town centre' within their territory, reflecting their polycentric nature. It must be noted that this variable does not measure as-the-crowfly distance to town centres, but rather travel time by walking or public transport. As such, it reflects to some extent variations in levels of public transport service, which is arguably appropriate for a measure of urbanity. Further to the analysis presented in this article, we have tested the inclusion in the regression models of a measure of population density as a third indicator of urbanity, finding no support for its inclusion.

The second set of predictors refers to accessibility to airports. We use Journey Time Statistics estimates of travel time by car and public transport from each LSOA to the 12 English airports that had at least $1 \%$ of total UK terminal passengers in 2015 (roughly corresponding to at least one million passengers per year). We use this information to compute two variables: i) travel time to the nearest airport; and ii) number of airports that can be reached within 60 minutes. For both variables, we considered travel time by car if the respondent's household had at least one car, and by public transport otherwise. As such, these predictors consider the accessibility differ- ential between households with and without cars. A third predictor-number of annual passengers at the nearest airport-captures level of service differences between airports, based on Civil Aviation Authority data for 2012 (Civil Aviation Authority, n.d.).

A third set of predictors covers migration background and social network dispersion. As an indicator of migration background, we use the UKHLS 'migration generation' variable, which distinguishes between respondents in the 'first generation' (not born in the UK), the second (at least one parent born abroad) and third generation (grandparents born abroad), and others (referred to as 'fourth generation or higher' in the dataset). For a minority of respondents with missing information on parents and/or grandparents, we assume that these were UK-born. We further distinguish between first generation migrants who have moved to the UK in the five years prior to the Wave 4 interview (i.e., since 2007-2008) and others. The resulting variable includes five categories and combines information on migration generation and (for first generation migrants) year of arrival in the UK. For the sake of simplicity, in the remainder of the article we refer to this variable as 'migration generation.' We further include a predictor for self-reported ethnicity, distinguishing between the 'White British' majority and the main minority groups in the UK ('Other White,' Asian, Blacks, and others). We capture the geographical dispersion of social networks with three variables: i) share of friends living in the local area (note that the definition of what 'local area' meant was left up to the respondents); ii) whether at least one of three 'best friends' lives abroad; and iii) whether any 'close family' member (i.e., parents or children) lives abroad.

The fourth set of predictors includes household-level measures of car ownership (binary variable) and car use. UKHLS respondents reported the approximate number of miles driven in the previous 12 months. We compute the total mileage driven by all household members, as we expect trade-offs between expenditure on cars and flights to be made based on household income.

Finally, we include several socio-economic control variables that previous research found to be associated with air travel (e.g., Alcock et al., 2017; Bruderer Enzler, 2017; Demoli \& Subtil, 2019; Dobruszkes, RamosPérez, \& Decroly, 2019; Reichert \& Holz-Rau, 2015). These include age, sex, net household monthly income (adjusted for taxes and housing benefits, equivalised after housing costs), education, employment status, as well as whether the respondent was in a cohabiting couple, was responsible for children under 16 years old, and had a long-standing illness or disability. The 'responsibility for children' variable refers to whether the individual was the responsible adult for cohabiting children, and not to household composition (although the two are obviously related). In households with two parents, this indicator is typically non-zero for the mother. We include this variable as we assume it is more closely associated with air travel than household composition. 


\subsection{Methods}

Our analysis consists of two steps. We start by presenting a bivariate analysis of the association between the main variables of interest and GHG emissions from air travel, then the results of multivariate analysis. We adopt a 'two-stage' approach to the multivariate analysis, whereby participation in air travel (i.e., having non-zero emissions) and the level of emissions (for respondents with a non-zero value) are modelled separately. The first stage (selection equation) consists of a logistic regression model, while for the second (outcome equation) we adopt Ordinary Least Square (OLS) regression with a log-transformed dependent variable. The two-stage approach and the log-transformation are justified in light of the high share of respondents who reported taking no flights, and the long-tailed distribution in the GHG emissions of respondents who took flights. We report coefficients for OLS models based on the full sample and non-transformed dependent variables separately in the supplementary material. These coefficients provide estimates of the overall magnitude (although not the statistical significance) of the effects.

As sensitivity testing, we conducted the same analysis using an alternative modelling approach, namely a two-step Heckman model (excluding the variable longstanding illness or disability from the second stage), obtaining results that are broadly consistent with those presented here. The Heckman model is able to calculate unbiased coefficients and significance levels. In this article, we present the results of the two-stage models as they are easier to interpret, while the corresponding Heckman models are included in the supplementary material.

Other models have been developed to overcome the limitations of Heckman models, including 'multiple discrete-continuous extreme value models' (MDCEV), which explicitly take account of discrete and continuous choice data (e.g., Lu, Hess, Daly, \& Rohr, 2017). In the context of our analysis, MDCEV would allow the exploration of variable substitution patterns between UK-based flights, continental flights, and long-haul flights. In this article, however, we present the results for two-stage and Heckman models, for three reasons: i) for ease of interpretation; ii) for consistency and comparability with previous studies on emissions from long-distance travel (e.g., Czepkiewicz, Ottelin, et al., 2018; Reichert, Holz-Rau, \& Scheiner, 2016); and iii) because questions about patterns of substitution between air travel segments are outside of the immediate interest of this article (although they are an interesting direction for future research).

We present four versions of both two-stage and Heckman regression models, reflecting the sequential adjustment of covariates:

1. Model 1, including the main spatial variables of interest and basic socio-economic control variables;
2. Model 2: further adjusted for migration generation, ethnicity, and social network variables;

3. Model 3: further adjusted for accessibility to airports;

4. Model 4: further adjusted for car ownership and use.

Model 1 tests the first set of hypotheses set out in Section 3, concerning the net association between urbanity and air travel. The sequential adjustment procedure provides evidence to test the second set of hypotheses, by showing whether and how the coefficients associated with living in urban areas and in closer proximity to town centres change when controlling for the three sets of intervening factors. We performed a collinearity test on the fully adjusted model (Model 4), obtaining no Variance Inflation Factor value higher than four.

\section{Results}

More than half of respondents in the analysis sample (57.3\%) reported zero flights. Among those who did report flights, the distribution of GHG emissions is highly positively skewed (median: $1373 \mathrm{kgCO}_{2} \mathrm{e}$; mean: 3135; standard deviation: 4491; skewness: 10.29). This means that there is a long tail of high values, corresponding to individuals who flied frequently and/or over long distances in the year prior to the interview.

A bivariate analysis of the associations between GHG emissions and the main predictors (Table 1) mostly confirms theoretical expectations. Participation in air travel and GHG emissions are highest for London residents. Outside of London, however, there is no clear urbanrural gradient, with slightly higher levels of air travel in rural area than in urban and conurbation areas (Figure 2). Emissions from air travel are somewhat higher for people living in closer proximity to town centres (Table 1).

There is a clear gradient in both participation and emissions across different migration generations, with particularly high levels of air travel among recent firstgeneration migrants. All minority ethnic groups have higher average emissions than 'White British,' although Blacks also have the highest non-participation rate. There is a strong association between geographical dispersion of social networks and emissions. We find higher emission and participation levels for respondents with better accessibility to large airports. Levels of air travel are higher for respondents with access to household cars and increase with mileage.

Patterns of association between GHG and basic socio-economic control variables (see Table SM2 in the Supplementary File) are broadly in line with the literature, with higher levels of air travel among respondents in employment, with higher income, and with tertiary education, as well as males, and among individuals in the 30 to 59 years old age band, and those in a cohabiting relationship. Respondents with long-standing illness or disability and those with responsibility for children 
(a) Participation in air travel

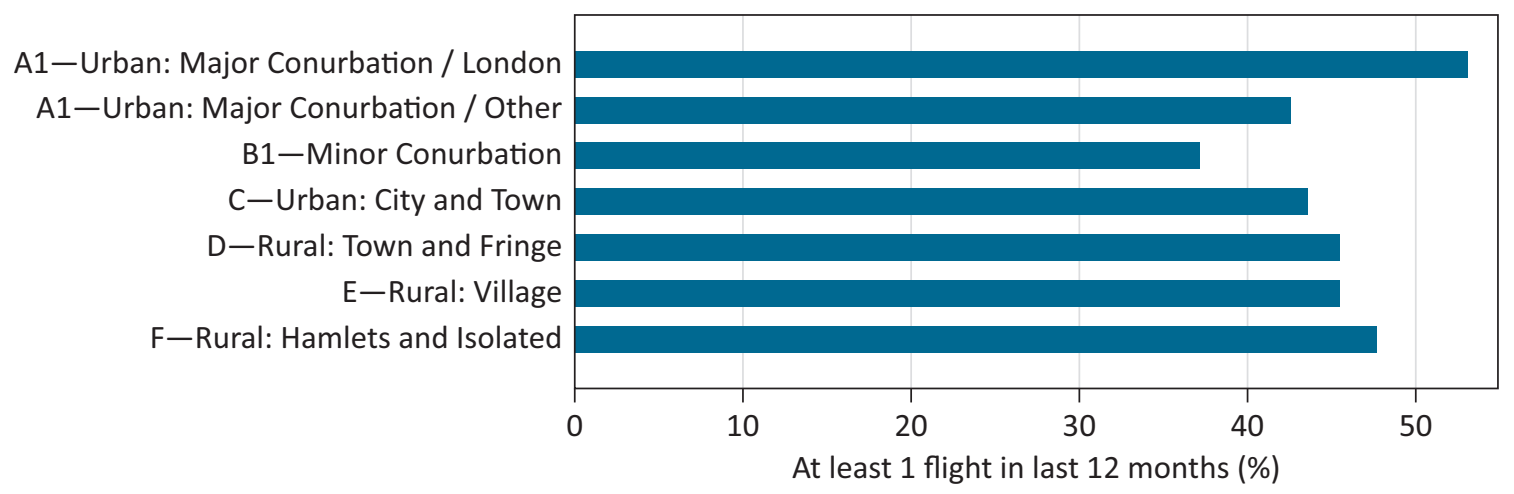

(b) GHG emissions (excluding zero values)

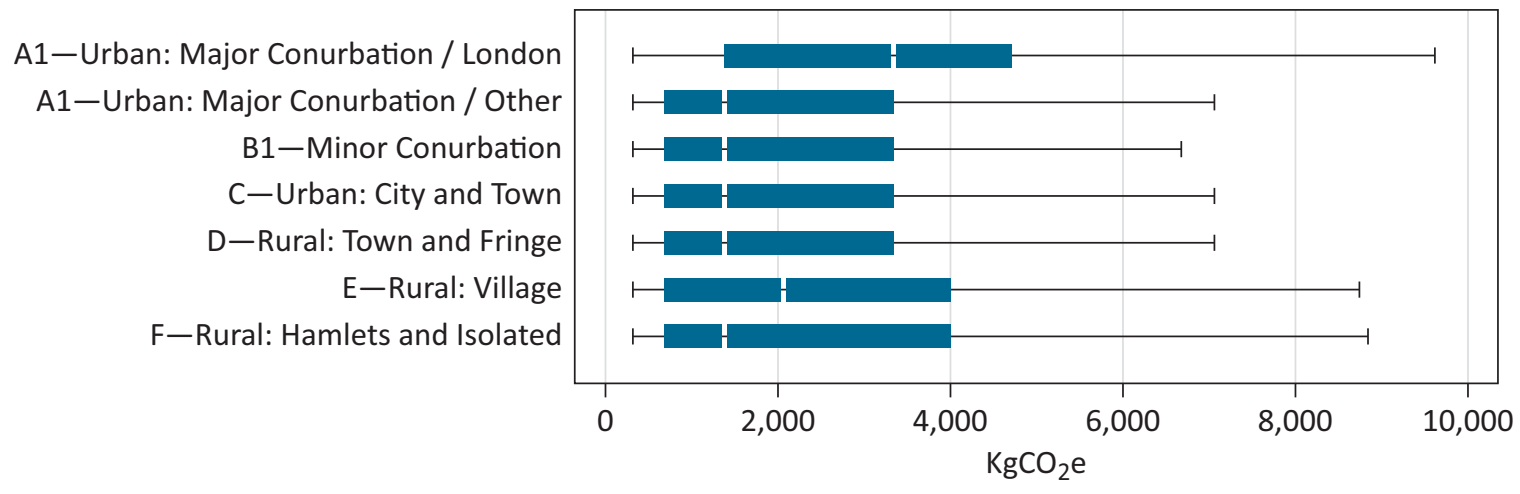

Figure 2. Participation in private air travel (panel a, $N=16,696$ ) and distribution of associated GHG emissions for respondents with non-zero values (panel $b, N=7,518$ ), by categories of the rural-urban classification. Note: The boxplots in panel b do not display outside values.

reported lower average levels of air travel. Note that the effect of income is particularly large, with average GHG emissions among respondents in the top income quintile nearly four times as large as for the bottom quintile.

The two-stage regression analysis (Table 2) shows that when controlling for basic socio-economic correlates (Model 1), there is no statistically significant difference between types of area, except for London and (to a lesser extent) rural villages, where emissions are higher. The coefficients for London change greatly in the adjusted models though. In Model 2, we control for migration generation and social networks: Here we find no significant association between London and the level of emissions (in the OLS model), while the coefficient for participation in air travel (in the logit model) is still significant but of lower magnitude as compared to Model 1. When further controlling for accessibility to airports (Model 3), neither coefficient for London is statistically significant. This suggests that a large part of the association between London and participation in air travel is accounted for by better accessibility to airports, while greater emissions are mostly accounted for by an overrepresentation of people with migration background and/or spatially dispersed social networks. The association between living in rural villages and air travel emissions, however, is not modified in the adjusted models.
We find a positive association between living in closer proximity to town centres and emissions (for air travel participants), which is only marginally reduced in magnitude in Model 2 and 3. This suggests that those who live in closer proximity to town centres, when they do fly, tend to do so more often and/or to further destinations. The reasons for this cannot be identified in our analysis. Note, however, that the magnitude of the association is very weak, with the OLS analysis (see Table SM3 in the Supplementary File) showing that living one minute further away from the nearest town centre is associated with a reduction in air travel GHG of just $1 \mathrm{kgCO}_{2}$ e per year in the fully-adjusted model.

Model 2 confirms the positive association between air travel and first-generation migration background. With regard to social network dispersion, both having close friends abroad and having close family abroad are positively associated with air travel. The effect of the share of friends outside of the local area is not linear, as the 'half or less' category is positively associated with participation in air travel, while the 'more than half' category is not. This may be due to the correlation between this category and other migration background, ethnicity and social network variables that are being controlled for. Overall, the effect of migration background and social network dispersion predictors is large, with 
Table 1. Main independent variables: Group size and descriptive statistics for GHG emissions from air travel $(N=16,696)$.

\begin{tabular}{|c|c|c|c|c|}
\hline Variable & Value & $\begin{array}{l}\text { Group size } \\
(\%)\end{array}$ & $\begin{array}{c}\text { Zero flights } \\
\text { (\%) }\end{array}$ & $\begin{array}{l}\text { GHG emissions } \\
\left(\mathrm{kgCO}_{2} \mathrm{e}, \text { mean }\right)\end{array}$ \\
\hline \multirow{7}{*}{$\begin{array}{l}\text { Rural-urban } \\
\text { classification }\end{array}$} & A1-Urban: Major Conurbation/London & 14.9 & 47.6 & 2045 \\
\hline & A1-Urban: Major Conurbation/Other & 16.4 & 59.0 & 1187 \\
\hline & B1-Minor Conurbation & 3.8 & 66.4 & 804 \\
\hline & C-Urban: City and Town & 45.0 & 59.0 & 1217 \\
\hline & D-Rural: Town and Fringe & 9.6 & 57.4 & 1204 \\
\hline & E-Rural: Village & 5.8 & 57.3 & 1434 \\
\hline & F-Rural: Hamlets and Isolated Dwellings & 3.5 & 56.3 & 1379 \\
\hline \multirow{3}{*}{$\begin{array}{l}\text { Travel time to nearest } \\
\text { town centre by } \\
\text { public transport } \\
\text { or walking }\end{array}$} & Low (3-16 minutes) & 37.4 & [56.7] & 1454 \\
\hline & Medium (17-22 minutes) & 29.4 & [57.7] & 1271 \\
\hline & High ( 23 or more minutes) & 32.2 & {$[57.4]$} & 1262 \\
\hline \multirow[t]{5}{*}{ Migration generation } & 4 th + & 71.3 & 59.3 & 1187 \\
\hline & $3 r d$ & 7.6 & 56.8 & 1316 \\
\hline & 2nd & 9.3 & 55.4 & 1579 \\
\hline & 1 st $(5+$ years $)$ & 10.1 & 46.0 & 2017 \\
\hline & 1st (less than 5 years) & 0.7 & 42.9 & 3775 \\
\hline \multirow[t]{5}{*}{ Ethnicity } & White British & 85.9 & 58.4 & 1232 \\
\hline & Other White & 4.1 & 35.1 & 2349 \\
\hline & Asian or Asian British & 5.2 & 54.3 & 2173 \\
\hline & Black or Black British & 2.1 & 63.1 & 1409 \\
\hline & Other + Mixed & 1.8 & 54.0 & 1610 \\
\hline \multirow{3}{*}{$\begin{array}{l}\text { Friends outside } \\
\text { of local area }\end{array}$} & None & 14.3 & 68.4 & 830 \\
\hline & Half or less & 45.6 & 55.1 & 1310 \\
\hline & More than half & 39.0 & 55.6 & 1556 \\
\hline \multirow[t]{2}{*}{ Best friends abroad } & No & 91.4 & 58.6 & 1245 \\
\hline & Yes & 7.6 & 40.9 & 2453 \\
\hline \multirow[t]{2}{*}{ Close family abroad } & No & 92.1 & 58.5 & 1244 \\
\hline & Yes & 7.0 & 40.0 & 2571 \\
\hline \multirow{3}{*}{$\begin{array}{l}\text { Travel time to nearest } \\
\text { large airport }\end{array}$} & Low (10-45 minutes) & 34.7 & 48.8 & 1708 \\
\hline & Medium (46-77 minutes) & 32.5 & 57.8 & 1275 \\
\hline & High (78 or more minutes) & 31.8 & 65.9 & 996 \\
\hline \multirow{3}{*}{$\begin{array}{l}\text { Number of airports } \\
\text { within } 60 \text { minutes } \\
\text { travel time }\end{array}$} & None & 47.6 & 63.8 & 1049 \\
\hline & 1 & 35.3 & 54.0 & 1409 \\
\hline & 2 or more & 16.1 & 45.0 & 2035 \\
\hline \multirow{3}{*}{$\begin{array}{l}\text { Annual passengers } \\
\text { at nearest large } \\
\text { airport (millions) }\end{array}$} & Low (5 or less) & 34.3 & 58.5 & 1209 \\
\hline & Medium (5-18) & 33.5 & 59.2 & 1226 \\
\hline & High (18 or more) & 31.2 & 53.8 & 1598 \\
\hline \multirow[t]{2}{*}{ Cars in household } & No & 18.1 & 77.8 & 681 \\
\hline & Yes & 80.9 & 52.6 & 1484 \\
\hline \multirow{3}{*}{$\begin{array}{l}\text { Distance driven by } \\
\text { car in last } 12 \text { months } \\
\text { (household total; } \\
\text { thousand miles) }\end{array}$} & Low (4 or less) & 34.4 & 70.4 & 847 \\
\hline & Medium (4-12) & 33.6 & 53.9 & 1476 \\
\hline & High (12 or more) & 31.0 & 46.3 & 1732 \\
\hline
\end{tabular}

Notes: Values between square brackets indicate that there is no statistically significant difference between the categories of the independent value (Chi-square and t-tests at $\mathrm{p}<0.05$ ). Continuous predictors were categorised into three groups (low/medium/high) based on terciles of the distribution. 
Table 2. Parameter estimates for two-stage regression models of $\mathrm{GHG}$ emissions $\left(\mathrm{kgCO}_{2} \mathrm{e}\right)$ from air travel, including selection equation (Logit-participation in air travel) and outcome equation (OLS-emissions of air travellers, log-transformed).

\begin{tabular}{|c|c|c|c|c|c|c|c|c|}
\hline & \multicolumn{2}{|c|}{ Model 1} & \multicolumn{2}{|c|}{ Model 2} & \multicolumn{2}{|c|}{ Model 3} & \multicolumn{2}{|c|}{ Model 4} \\
\hline & Logit & OLS & Logit & OLS & Logit & OLS & Logit & OLS \\
\hline & Coef. (b) & $\begin{array}{c}\text { Coef. (b) } \\
\text { [in } \log (\mathrm{kg})]\end{array}$ & Coef. (b) & $\begin{array}{c}\text { Coef. (b) } \\
\text { [in } \log (\mathrm{kg})]\end{array}$ & Coef. (b) & $\begin{array}{c}\text { Coef. (b) } \\
\text { [in } \log (\mathrm{kg})]\end{array}$ & Coef. (b) & $\begin{array}{c}\text { Coef. (b) } \\
{[\text { in } \log (\mathrm{kg})]}\end{array}$ \\
\hline \multicolumn{9}{|l|}{ Rural-urban classification (ref.cat.: C-Urban: City and Town) } \\
\hline A1-Urban: Major Conurbation/London & $0.39 * * *$ & $0.21 * * *$ & $0.3 * * *$ & 0.08 & 0.06 & 0.02 & $0.25 * *$ & 0.04 \\
\hline A1-Urban: Major Conurbation/Other & 0.08 & 0.01 & 0.12 & 0.01 & -0.03 & 0.01 & 0.06 & 0.01 \\
\hline B1-Minor Conurbation & -0.11 & -0.09 & -0.06 & -0.08 & -0.07 & -0.04 & -0.03 & -0.03 \\
\hline D-Rural: Town and Fringe & -0.01 & -0.04 & -0.01 & -0.03 & 0.02 & -0.02 & -0.01 & -0.03 \\
\hline E-Rural: Village & -0.10 & $0.12 *$ & -0.10 & $0.13 *$ & -0.03 & $0.14 *$ & -0.09 & $0.13 *$ \\
\hline F-Rural: Hamlets and Isolated Dwellings & -0.16 & -0.03 & -0.16 & -0.02 & -0.11 & -0.01 & -0.17 & -0.02 \\
\hline $\begin{array}{l}\text { Travel time to nearest town centre by public transport or } \\
\text { walking (minutes) }\end{array}$ & 0.002 & $-0.004 *$ & 0.002 & $-0.003 *$ & 0.003 & $-0.003 *$ & 0.001 & $-0.004^{*}$ \\
\hline \multicolumn{9}{|l|}{ Income quintile (ref. cat.: $1^{\text {st }}$ ) } \\
\hline $2^{\text {nd }}$ & $0.18 *$ & -0.08 & $0.21 * *$ & -0.05 & $0.17^{*}$ & -0.05 & 0.10 & -0.05 \\
\hline $3^{\text {rd }}$ & $0.55 * * *$ & -0.02 & $0.60 * * *$ & 0.06 & $0.56 * * *$ & 0.05 & $0.46 * * *$ & 0.05 \\
\hline $4^{\text {th }}$ & $0.97 * * *$ & 0.08 & $1.00 * * *$ & $0.16 * *$ & $0.95 * * *$ & $0.16 * *$ & $0.84 * * *$ & $0.15 * *$ \\
\hline $5^{\text {th }}$ & $1.60 * * *$ & $0.33 * * *$ & $1.60 * * *$ & $0.42 * * *$ & $1.60 * * *$ & $0.41 * * *$ & $1.40 * * *$ & $0.39 * * *$ \\
\hline Tertiary education qualification (dummy) & $0.39 * * *$ & $0.09 * * *$ & $0.34 * * *$ & 0.04 & $0.32 * * *$ & 0.04 & $0.32 * * *$ & 0.04 \\
\hline \multicolumn{9}{|l|}{ Employment status (ref. cat.: In employment) } \\
\hline Retired & $-0.37 * * *$ & -0.05 & $-0.36 * * *$ & -0.05 & $-0.35 * * *$ & -0.05 & $-0.30 * * *$ & -0.04 \\
\hline Other (non-employed, non-retired) & $-0.37 * * *$ & $0.08 *$ & $-0.36 * * *$ & 0.06 & $-0.35 * * *$ & 0.06 & $-0.31 * * *$ & $0.07^{*}$ \\
\hline \multicolumn{9}{|l|}{ Age (ref.cat. 16-29 years old) } \\
\hline $30-59$ years old & $-0.24 * * *$ & $0.12 * *$ & $-0.30 * * *$ & $0.11 * *$ & $-0.29 * * *$ & $0.11 * *$ & $-0.26 * * *$ & $0.12 * *$ \\
\hline $60-74$ years old & -0.04 & $0.15 * *$ & -0.07 & $0.18 * * *$ & -0.07 & $0.18 * * *$ & -0.04 & $0.20 * * *$ \\
\hline $75+$ years old & $-0.71 * * *$ & 0.08 & $-0.74 * * *$ & 0.12 & $-0.70 * * *$ & 0.12 & $-0.61 * * *$ & 0.14 \\
\hline Cohabiting couple (dummy) & $0.33 * * *$ & 0.02 & $0.31 * * *$ & 0.01 & $0.28 * * *$ & 0.01 & $0.19 * * *$ & 0.00 \\
\hline Female (dummy) & $0.18 * * *$ & -0.02 & $0.19 * * *$ & 0.00 & $0.19 * * *$ & 0.00 & $0.21 * * *$ & 0.00 \\
\hline Responsible for children $<16$ years old (dummy) & $-0.33 * * *$ & $-0.19 * * *$ & $-0.36 * * *$ & $-0.20 * * *$ & $-0.37 * * *$ & $-0.20 * * *$ & $-0.38 * * *$ & $-0.20 * * *$ \\
\hline Long-standing illness or disability (dummy) & $-0.36 * * *$ & $-0.09 * * *$ & $-0.34 * * *$ & $-0.08 * *$ & $-0.33 * * *$ & $-0.08 * *$ & $-0.31 * * *$ & $-0.07^{* *}$ \\
\hline
\end{tabular}


Table 2. (Cont.) Parameter estimates for two-stage regression models of $\mathrm{GHG}$ emissions $\left(\mathrm{kgCO}_{2} \mathrm{e}\right)$ from air travel, including selection equation (Logit-participation in air travel) and outcome equation (OLS-emissions of air travellers, log-transformed).

\begin{tabular}{|c|c|c|c|c|c|c|c|c|}
\hline & \multicolumn{2}{|c|}{ Model 1} & \multicolumn{2}{|c|}{ Model 2} & \multicolumn{2}{|c|}{ Model 3} & \multicolumn{2}{|c|}{ Model 4} \\
\hline & Logit & OLS & Logit & OLS & Logit & OLS & Logit & OLS \\
\hline & Coef. (b) & $\begin{array}{c}\text { Coef. (b) } \\
{[\text { in } \log (\mathrm{kg})]}\end{array}$ & Coef. (b) & $\begin{array}{c}\text { Coef. (b) } \\
{[\text { in } \log (\mathrm{kg})]}\end{array}$ & Coef. (b) & $\begin{array}{c}\text { Coef. (b) } \\
{[\text { in } \log (\mathrm{kg})]}\end{array}$ & Coef. (b) & $\begin{array}{c}\text { Coef. (b) } \\
{[\text { in } \log (\mathrm{kg})]}\end{array}$ \\
\hline \multicolumn{9}{|l|}{ Migration generation (ref. cat.: $4^{\text {th }}+$ ) } \\
\hline $3^{\text {rd }}$ & & & 0.03 & 0.05 & 0.01 & 0.05 & 0.03 & 0.05 \\
\hline $2^{\text {nd }}$ & & & 0.11 & 0.02 & 0.11 & 0.01 & 0.11 & 0.01 \\
\hline 1 st (5+ years) & & & $0.28 * *$ & 0.02 & $0.28 * *$ & 0.01 & $0.3 * *$ & 0.02 \\
\hline 1st (less than 5 years) & & & 0.03 & $0.47^{* *}$ & 0.05 & $0.48 * * *$ & 0.14 & $0.49 * * *$ \\
\hline \multicolumn{9}{|l|}{ Ethnic group (ref. cat.: White British) } \\
\hline Other White & & & $0.35 *$ & -0.05 & $0.34 *$ & -0.05 & $0.34 *$ & -0.05 \\
\hline Asian or Asian British & & & -0.14 & $0.51 * * *$ & -0.18 & $0.51 * * *$ & -0.20 & $0.51 * * *$ \\
\hline Black or Black British & & & $-0.49 * * *$ & $0.23 * *$ & $-0.49 * * *$ & $0.25 * *$ & $-0.42 * *$ & $0.26 * *$ \\
\hline Other + Mixed & & & -0.082 & 0.15 & -0.09 & 0.16 & -0.05 & 0.16 \\
\hline \multicolumn{9}{|l|}{ Friends outside of local area (ref.cat.: none) } \\
\hline half or less & & & $0.22 * * *$ & 0.02 & $0.20 * * *$ & 0.02 & $0.19 * *$ & 0.02 \\
\hline more than half & & & 0.08 & 0.08 & 0.06 & 0.08 & 0.05 & 0.08 \\
\hline Best friends abroad (dummy) & & & $0.33 * * *$ & $0.14 * * *$ & $0.32 * * *$ & $0.14 * * *$ & $0.32 * * *$ & $0.14 * * *$ \\
\hline Close family abroad (dummy) & & & $0.51 * * *$ & $0.28 * * *$ & $0.52 * * *$ & $0.28 * * *$ & $0.56 * * *$ & $0.28 * * *$ \\
\hline Travel time to nearest large airport (hours) & & & & & $-0.19 * * *$ & 0.00 & $-0.12 *$ & 0.00 \\
\hline Number of airports within 60 minutes travel time & & & & & $0.12 * *$ & 0.04 & 0.06 & 0.04 \\
\hline Annual passengers at nearest large airport (millions) & & & & & 0.001 & $0.002 * *$ & 0.001 & $0.002 * *$ \\
\hline Cars in household (dummy) & & & & & & & $0.53 * * *$ & -0.02 \\
\hline $\begin{array}{l}\text { Distance driven by car in last } 12 \text { months (household total; } \\
\text { thousand miles) }\end{array}$ & & & & & & & $0.005^{* *}$ & $0.003 * *$ \\
\hline Constant & $-1.0 * * *$ & $7.4 * * *$ & $-1.2 * * *$ & $7.2 * * *$ & $-1.0 * * *$ & $7.1 * * *$ & $-1.5 * * *$ & $7.1 * * *$ \\
\hline $\mathrm{N}$ & 16696 & 7518 & 16696 & 7518 & 16696 & 7518 & 16696 & 7518 \\
\hline Pseudo- $R^{2} / R^{2}$ & 0.11 & 0.06 & 0.12 & 0.09 & 0.13 & 0.10 & 0.13 & 0.10 \\
\hline AIC & 22235 & 20614 & 22016 & 20342 & 21921 & 20329 & 21805 & 20320 \\
\hline
\end{tabular}

Note: $* p<0.05, * * p<0.01, * * * p<0.001$. 
e.g., having close family members abroad being associated with an additional $776 \mathrm{kgCO}_{2} \mathrm{e}$ for air travel per year in the fully adjusted model (see Table SM3 in the Supplementary File).

The effect of ethnic minority background is complex. Non-British ('other') Whites are more likely to participate in air travel than any other ethnic group, but those of them who fly do not tend to generate higher levels of emissions, perhaps because of shorter flights to Europe. Conversely, Asians, Blacks, and those with 'other or mixed' background are less likely to participate in air travel, but those of them who do tend to fly longer distances as compared to the White British majority (Table 2). The overall impact on GHG emissions is strongly positive for Asians, but negative for Blacks and respondents with 'other and mixed' background (see Table SM3 in the Supplementary File).

Regarding accessibility to airports, Model 3 shows higher participation in air travel for those who live closer to a large airport, and for those who are able to reach several airports within 60 minutes travel time, even after controlling for confounders (Table 2). The number of passengers at the nearest airport is associated with an increase in GHG emissions for those who fly, although of small magnitude (see Table SM3 in the Supplementary File).

Contrary to expectations, we find a net positive association between car ownership and participation in air travel, as well as between car mileage and both dimensions of air travel (Table 2, Model 4), although the magnitude of the latter coefficient is not very large (see Table SM3 in the Supplementary File). The inclusion of these variables modifies the coefficients for London which, in the fully adjusted model, is again positively associated with participation in air travel. This can be interpreted as follows: Londoners fly more than residents of other areas, if one considers lower car ownership and use in London, and that car drivers tend to fly more. Conversely, in Model 4 the positive association between the number of airports that one can reach within 60 minutes and participation in air travel loses significance. This suggests that access to a car improves access to airports, and that this explains part-but only part-of why car owners fly more.

Regarding socio-economic control variables, the multivariate findings broadly confirm the bivariate analysis, with high income, tertiary education, employment, couple cohabitation, and middle adulthood all associated with greater GHG emissions. As expected, the impact of income is particularly large, with the top income quintile emitting roughly $1,600 \mathrm{kgCO}_{2} \mathrm{e}$ more than the bottom quintile when controlling for other factors (see Table SM3 in the Supplementary File). Conversely, being responsible for children and long-standing illness or disability are associated with substantial reductions in GHG. It is interesting to note however that when other factors (including notably retirement and disability) are controlled for, the young elderly (60 to 74 years old) have the highest GHG emissions from air travel (see Table SM3 in the Supplementary File). Younger adults (16 to 29 years old) appear more likely than other age groups to fly at least once a year, although on the whole they emit less GHG. Females are more likely than men to participate in air travel when responsibility for children is controlled for (Table 2), although the magnitude of the effect in terms of GHG is trivial (see Table SM3 in the Supplementary File). This suggests that lower levels of air travel among women are largely due to childcare responsibility.

The results of the corresponding Heckman models (see Table SM4 in the Supplementary File) are largely consistent with those discussed above, showing only marginal differences in terms of statistical significance of single coefficients.

Further to the analysis presented here, we tested whether there is evidence of a rebound effect among respondents in the lower-middle income groups, as suggested in the literature (Czepkiewicz, Heinonen, et al., 2020; Ottelin et al., 2014, 2017). The rationale is that, since both air travel and car driving are relatively cheap for higher income households, one would expect to see a rebound effect only among households with more limited resources. To test this conjecture, in Model 5 (see Table SM5 in the Supplementary File) we include interaction terms between income and car ownership and use. We find no evidence of a rebound effect between car ownership and mileage and air travel.

\section{Discussion and Conclusions}

Our findings provide qualified support for the first set of hypotheses: Levels of private air travel are higher in the largest English conurbation (London), and among those living in closer proximity to city centres, even after controlling for basic socio-economic characteristics such as income, age, sex, and household composition. This is consistent with previous research (Czepkiewicz, Heinonen, et al., 2018). In contrast with previous studies showing a clear urban-rural gradient in air travel (e.g., Demoli \& Subtil, 2019; Reichert \& Holz-Rau, 2015), we find no clear difference between rural areas and urban areas other than London (including other large conurbations), and a persistent positive association between rural villages and air travel emissions. A possible explanation is that in England rural villages attract people who are particularly wealthy, educated, and/or internationally connected, in ways that are not entirely captured by our predictors.

We find evidence that the association between London residence and air travel is partly due to better airport accessibility, as well as to the overrepresentation of migrants, ethnic minorities, and people with otherwise dispersed social networks. This confirms hypotheses that had been put forward in the literature, but for which scant evidence existed to date. However, when controlling for all predictors (including car ownership and use), we find a residual positive association between London residence and participation in air travel. This suggests that other factors might also be at play. 
Unlike for London residence, greater levels of air travel among people who live in closer proximity to city centres are largely not due to any of the factors considered here, although the magnitude of the association is very weak. Recent research suggests that this association may be due to the cosmopolitan attitudes of urban core residents (Czepkiewicz et al., 2019; Czepkiewicz, Klaas, et al., 2020). This factor could not be included in our study as it is not available within the survey, although one would expect it to correlate to some extent with migration background and social networks abroad. More research is needed on the interrelationships between these factors, notably from a life course perspective (Mattioli, 2020).

Against our hypothesis, the study finds a net positive association between car ownership and use and air travel. This contradicts the hypothesis of a tradeoff between the two but is consistent with studies that found a neutral or positive association (see Section 2). Since car ownership and use are lower in London than elsewhere, this implies that a 'rebound effect' is not responsible for higher levels of air travel in the British capital. The reasons for the positive association are not clear from our analysis though. Apart from shorter journey times (which are controlled for in our models), research on airport surface access suggests that people find driving more convenient than public transport in terms of cost, comfort, reliability, and ease of transporting luggage (Budd, 2019). This may discourage households without a car from flying. Another possible explanation is that underlying attitudinal or lifestyle factors are associated with both car and air travel, and account for the observed positive association. Finally, it might be that in an island country like the UK, where a very high share of international travel is by plane, car and air travel are not perceived as substitutes for long-distance travel.

Our results have three main policy implications. First, from an urban planning perspective, they are not supportive of the thesis that encouraging urbanisation and/or urban densification would increase air travel and thus backfire in terms of transport emission. This thesis is predicated on the 'compensation hypothesis' (which we did not test here) and the 'rebound effect' (for which we find no evidence). We find evidence that better access to airports and social network dispersion are important factors in explaining why Londoners fly more, which tends to suggest that alternative explanations for higher levels of air travel in large urban areas are of secondary importance.

Second, the association between air travel and the size and proximity of airports could be interpreted as suggesting that air travel supply induces demand to some extent. This would provide support for a moratorium on airport expansion for the sake of the climate (Stay Grounded, 2019). Yet one could also see the association as demand-led, as airline hubs prefer to locate near large markets. Global cities like London, with concentrations of high-skilled workforce and migrants, tend to pro- vide such conditions. Residents with international lives and/or careers might self-select into such cities, precisely because of the ease of air travel that they provide (Dobruszkes, Lennert, \& Van Hamme, 2011). Conversely, airport hubs may result in overprovision and induced demand among those who happen to live nearby. While our analysis controls for many of the demand-side factors that might explain the association (e.g., migration background, social networks, and education), the recursive causality between supply and demand must be kept in mind and investigated further.

Finally, the positive association between car travel and air travel, if confirmed, would suggest that there are synergies between measures aimed at reducing car ownership and use and those aimed at curbing air travel. This would be good news for sustainable transport policy, since car and air travel account for most transport emissions.

\section{Acknowledgments}

This research was funded by the German Research Foundation as part of the research project "Advancing knowledge of long-distance travel: Uncovering its connections to mobility biography, migration, and daily travel" (2018-2022, Project Number: SCHE 1692/10-1). Understanding Society is an initiative funded by the Economic and Social Research Council and various Government Departments, with scientific leadership by the Institute for Social and Economic Research, University of Essex, and survey delivery by NatCen Social Research and Kantar Public. The research data are distributed by the UK Data Service. We are indebted to Frédéric Dobruszkes for input on the interpretation of the findings.

\section{Conflict of Interests}

The authors declare no conflict of interests.

\section{Supplementary Material}

Supplementary material for this article is available online in the format provided by the authors (unedited).

\section{References}

Alcock, I., White, M. P., Taylor, T., Coldwell, D. F., Gribble, M. O., Evans, K. L., . . F Fleming, L. E. (2017). 'Green' on the ground but not in the air: Pro-environmental attitudes are related to household behaviours but not discretionary air travel. Global Environmental Change, 42, 136-147.

Bruderer Enzler, H. (2017). Air travel for private purposes: An analysis of airport access, income and environmental concern in Switzerland. Journal of Transport Geography, 61, 1-8.

Budd, T. (2019). The role of airport surface access in the 
passenger journey. In A. Graham \& F. Dobruszkes (Eds.), Air transport: A tourism perspective (pp. 165-175). Amsterdam: Elsevier.

Civil Aviation Authority. (n.d.). Airport data 1990 onwards. Civil Aviation Authority. Retrieved from https://www.caa.co.uk/Data-and-analysis/UKaviation-market/Airports/Datasets/UK-Airportdata/Airport-data-1990-onwards

Czepkiewicz, M., Árnadóttir, Á., \& Heinonen, J. (2019). Flights dominate travel emissions of young urbanites. Sustainability, 11(22), 6340.

Czepkiewicz, M., Heinonen, J., Næss, P., \& Stefansdóttir, H. (2020). Who travels more, and why? A mixedmethod study of urban dwellers' leisure travel. Travel Behaviour and Society, 19, 67-81.

Czepkiewicz, M., Heinonen, J., \& Ottelin, J. (2018). Why do urbanites travel more than do others? A review of associations between urban form and long-distance leisure travel. Environmental Research Letters, 13(7), 073001.

Czepkiewicz, M., Klaas, V., \& Heinonen, J. (2020). Compensation or cosmopolitan attitudes: Explaining leisure travel of Nordic urbanites. Travel Behaviour and Society, 21, 167-187.

Czepkiewicz, M., Ottelin, J., Ala-Mantila, S., Heinonen, J., Hasanzadeh, K., \& Kyttä, M. (2018). Urban structural and socioeconomic effects on local, national and international travel patterns and greenhouse gas emissions of young adults. Journal of Transport Geography, 68, 130-141.

Demoli, Y., \& Subtil, J. (2019). Boarding classes: Mesurer la démocratisation du transport aérien en France (1974-2008) [Boarding classes: Measuring the 'democratisation' of air travel in France (1974-2008)]. Sociologie, 10(2), 131-151.

Department for Environment, Food and Rural Affairs \& Department of Energy and Climate Change. (2015). Conversion factors 2015-Full set (for advanced users). GOV.UK. Retrieved from https://www.gov.uk/ government/publications/greenhouse-gasreporting-conversion-factors-2015

Department for Transport. (2019). Journey time statistics: Notes and definitions. London: Department for Transport.

Dobruszkes, F., Lennert, M., \& Van Hamme, G. (2011). An analysis of the determinants of air traffic volume for European metropolitan areas. Journal of Transport Geography, 19(4), 755-762.

Dobruszkes, F., Ramos-Pérez, D., \& Decroly, J.-M. (2019). Reasons for flying. In A. Graham \& F. Dobruszkes (Eds.), Air transport: A tourism perspective (pp. 23-39). Amsterdam: Elsevier.

Graver, B., Zhang, K., \& Rutherford, D. (2019). $\mathrm{CO}_{2}$ emissions from commercial aviation, 2018 (Working Paper 2019-16). Washington, DC: The International Council on Clean Transportation.

Hunecke, M., \& Toprak, A. (Eds.). (2014). Empowerment von Migrant_innen zum Klimaschutz-Konzepte, empirische Befunde und Handlungsempfehlungen [Empowering migrants to mitigate climate change: Concepts, empirical findings and policy recommendations]. Munich: Oekom.

Lu, H., Hess, S., Daly, A., \& Rohr, C. (2017). Measuring the impact of alcohol multi-buy promotions on consumers' purchase behaviour. Journal of Choice Modelling, 24, 75-95.

Mattioli, G. (2020). Towards a mobility biography approach to long-distance travel and 'mobility links.' In J. Scheiner \& H. Rau (Eds.), Mobility and travel behaviour across the life course: A dialogue between qualitative and quantitative research approaches (pp. 82-99). Cheltenham: Edward Elgar.

ODPM \& Centre for Advanced Spatial Analysis. (2002). Producing boundaries and statistics for town centres: London pilot study summary report. London: Office of the Deputy Prime Minister \& Centre for Advanced Spatial Analysis, University College London.

Office for National Statistics. (2013). 2011 rural urban classification. GOV.UK. Retrieved from https://www. gov.uk/government/statistics/2011-rural-urbanclassification

Ottelin, J., Heinonen, J., \& Junnila, S. (2014). Greenhouse gas emissions from flying can offset the gain from reduced driving in dense urban areas. Journal of Transport Geography, 41, 1-9.

Ottelin, J., Heinonen, J., \& Junnila, S. (2017). Rebound effects for reduced car ownership and driving. In S. Kristjánsdóttir (Ed.), Nordic experiences of sustainable planning: Policy and practice (pp. 263-283). New York, NY: Routledge.

Reichert, A., \& Holz-Rau, C. (2015). Mode use in longdistance travel. Journal of Transport and Land Use, 8(2), 87-105.

Reichert, A., Holz-Rau, C., \& Scheiner, J. (2016). GHG emissions in daily travel and long-distance travel in Germany: Social and spatial correlates. Transportation Research Part D: Transport and Environment, 49, 25-43.

Stay Grounded. (2019). Degrowth of aviation: Reducing air travel in a just way. Vienna: Stay Grounded.

Thurstain-Goodwin, M., \& Unwin, D. (2000). Defining and delineating the central areas of towns for statistical monitoring using continuous surface representations. Transactions in GIS, 4(4), 305-317.

University of Essex \& Institute for Social and Economic Research. (2018a). Understanding society: Waves 1-8, 2009-2017 and Harmonised BHPS: Waves 1-18, 1991-2009: Special licence access (Data collection, 10th ed.). UK Data Service. http://doi.org/10.5255/ UKDA-SN-6931-9

University of Essex \& Institute for Social and Economic Research. (2018b). Understanding society: Waves 1-8, 2009-2017: Special licence access, Census 2011 lower layer super output areas (Data collection, 8th ed.). UK Data Service. http://doi.org/10.5255/ UKDA-SN-7248-8 
University of Essex \& Institute for Social and Economic Research. (2019). Understanding society: Waves 1-9, 2009-2018: Special licence access, Census 2011 rural-urban indicators (Data collection, 7th ed.). UK Data Service. http://doi.org/10.5255/UKDA-SN7630-7

\section{About the Authors}

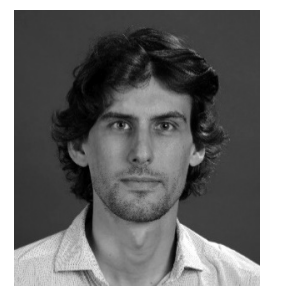

Giulio Mattioli is Research Fellow at the Department of Transport Planning, TU Dortmund University and Visiting Research Fellow at the School of Earth \& Environment, University of Leeds. He holds a PhD in European Urban and Local Studies from the University of Milan-Bicocca (Italy). His research interests include car dependence and carbon lock-in in the transport sector, the social drivers of long-distance travel, transport poverty, affordability and energy vulnerability, and the political economy of transport systems.

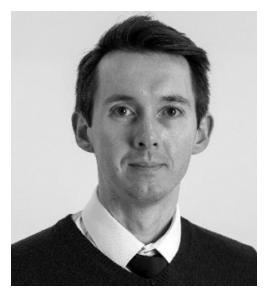

Craig Morton has been a Lecturer at Loughborough University since 2018. His research sits in the field of transport geography, where he applies spatial modelling techniques to understand the demand for mobility and how this relates to the wider environment.

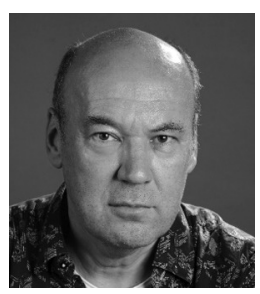

Joachim Scheiner received his PhD in Geography at Freie Universität Berlin. He is now a Professor in Transport Studies at the Faculty of Spatial Planning, TU Dortmund University. His research focuses on travel behaviour in the context of residential mobility, spatial development, and societal change. 